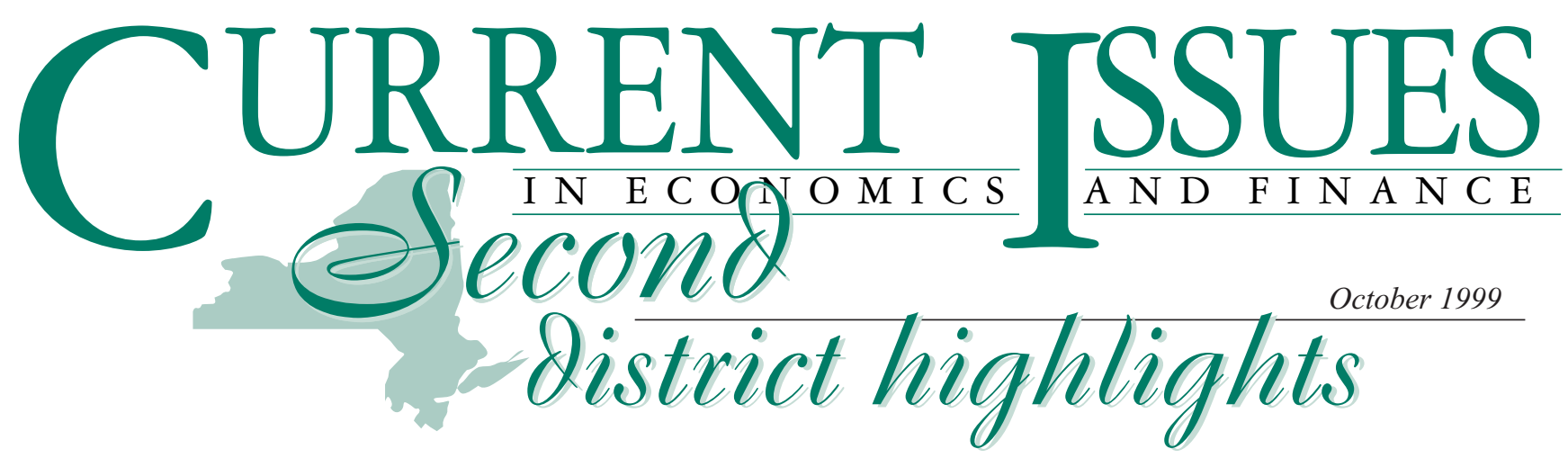

\title{
Two New Indexes Offer a Broad View of Economic Activity in the New York-New Jersey Region
}

James Orr, Robert Rich, and Rae Rosen

The ability to identify periods of expansion and contraction associated with business cycles has widespread implications for the economy. If consumers perceive wage growth as being strong and job security high, for example, they might make more purchases, whereas businesses that sense that the demand for their goods is slowing might defer investment in new equipment.

Unfortunately, it can be difficult to track the economy's performance because the individual data series used to determine economic patterns rarely provide a clear and immediate signal of changes in activity. At the national level, the U.S. Department of Commerce has responded to this problem by combining several macroeconomic data series into what is known as a coincident index - a single composite measure intended to gauge the current state of the aggregate economy. ${ }^{1}$ Today, the national coincident index provides a broad and timely measure of U.S. economic activity each month.

Regional economies, however, present more challenging problems. Like the national economy, these economies are subject to fluctuations in activity, but their business cycles are generally more difficult to monitor than national cycles. Indexes of economic activity are not widely available at the regional level, ${ }^{2}$ and national indexes are not likely to be useful if the economy in question is influenced strongly by local factors. Furthermore, indexes that might correspond closely with regional business cycles, such as gross state product (GSP), are reported only annually and with a lag of several years. Accordingly, economists who track regional activity typically rely on changes in a single series: nonfarm payroll employment by state or city. The series has the advantage of being reported monthly for a wide range of industries, yet by itself it may be too narrow to capture fully changes in the strength and direction of economic activity. ${ }^{3}$

In order to meet the need for a more comprehensive regional measure, we have developed two monthly coincident indexes of economic activity for the New YorkNew Jersey area. One is patterned after the national coincident index, and the other is based on a formal statistical model. In this issue of Second District Highlights, we describe the formulation of the two indexes and assess their usefulness in identifying trends in regional economic activity over the past few decades.

We use the indexes as tools to examine the region's current expansion and to date business cycles specific to New Jersey, New York State, and New York City. ${ }^{4}$ The timing and duration of the regional cycles prove to be very different from those of the national cycles, providing evidence that national expansions and contractions are not reflected evenly throughout the region. Although our tracking of the regional business cycles confirms that the nonfarm payroll employment series is a reasonably good indicator of the economy's movements, the coincident indexes yield fuller information about the nature of those movements. A final advantage of the indexes is their potential role in the creation of broad leading indexes - that is, measures that could predict cyclical changes in the New York-New Jersey region's economy. 


\section{Constructing THE Regional Indexes}

Our regional coincident indexes are the simple weighted index (SWI) and the estimated weighted index (EWI). The SWI is constructed using the Commerce Department's method of computing the national coincident index; the EWI is derived using a formal statistical model developed by Stock and Watson (see box).

Both of our indexes combine data at the regional level into a single composite measure to produce a monthly reading of the current state of economic activity. For New Jersey and New York State, we use information on four series: nonfarm payroll employment, real earnings (wages and salaries), the unemployment rate, and average weekly hours worked in the manufacturing sector. We exclude the unemployment rate for New York City because of recent changes in its cyclical behavior. ${ }^{5}$ Despite differences in construction, the SWI and the EWI are both essentially weighted averages of changes in the individual series.

The components of our indexes differ somewhat from those used in the national coincident index and in existing state coincident indexes. Specifically, ours use average weekly hours worked in manufacturing and the unemployment rate in place of the national index's measures of industrial production and manufacturing and retail sales. The substitution of these variables in our calculations reflects the unavailability of state and local area industrial production data and the 1996 discontinuation of the state and local retail sales series.

\section{A Closer Look at the Methodology Behind Coincident Indexes}

To construct our monthly regional coincident indexes - the simple weighted index (SWI) and the estimated weighted index (EWI) - we apply, respectively, the techniques used in the construction of national coincident indexes developed by the U.S. Department of Commerce and by Stock and Watson (1989). Here we provide a brief description of these alternative methodologies. ${ }^{\mathrm{a}}$

- The simple weighted index. We calculate the index as a weighted average of changes in the individual components. We follow the approach of the Department of Commerce, in which the weights are inversely related to the series' estimated volatility (measured by the standard deviation) and are constrained to sum to 1 . Thus, series that display greater (lesser) volatility will receive less (more) weight. In addition, the index employs only current values of the components. To construct the SWI, we interpolate the quarterly real earnings figures to produce monthly estimates.

- The estimated weighted index. Stock and Watson offer a more formal approach to the construction of a coincident index. Following their model, we assume that measures of economic activity share the influence of a single unobserved factor ("the state of the economy"). The coincident index is identified as this common factor and is a weighted average of current and lagged changes in the components. The weights sum to 1 and are determined by maximum likelihood estimation of the model using the Kalman filter. The EWI uses a mixed-frequency model that can accommodate both monthly and quarterly series and therefore avoids the need to interpolate the real earnings series.

Timeliness of our indexes is ensured by the fact that the data on payroll employment, the unemployment rate, and average weekly hours worked in the manufacturing sector are released monthly around seven weeks after month-end. However, real earnings are reported only quarterly, with a lag of approximately six months. To address the problem of missing observations, we use a model to generate forecasts for the two most recent quarterly observations on real earnings.

${ }^{\text {a }}$ More formally, the SWI and the EWI are given, respectively, by

$$
\begin{aligned}
& C_{t}^{S W I}=\sum_{i=1}^{n} w_{i} X_{t}^{i} \\
& C_{t}^{E W I}=\sum_{j=0}^{k_{1}} w_{1}^{j} X_{t-j}^{1}+\sum_{j=0}^{k_{2}} w_{2}^{j} X_{t-j}^{2}+\ldots+\sum_{j=0}^{k_{n}} w_{n}^{j} X_{t-j}^{n}, \\
& \text { where } X_{t-j}^{i} \text { is the (symmetrical) percentage change in the } i \text { th component in period } t-j, w_{i}^{j} \text { is the weight on } X_{t-j}^{i}, \\
& \text { and } w_{i}=\sum_{j=0}^{k} w_{i}^{j} \text { is the total weight on the } i \text { th component in the index. }
\end{aligned}
$$




\section{What the Indexes Tell Us about the Region}

New Jersey

The two coincident indexes reveal that the business cycles in New Jersey have diverged sharply from the national cycles. These disparities in the timing and duration of cyclical activity result from differences in the industrial structures of New Jersey and the nation as well as the influence of local factors on the state's economy.

The degree to which the state business cycle has deviated from the national cycle is evident in Chart 1. The chart plots the movements in our two regional indexes over the 1969-98 period along with indicators of state downturns and national recessions. Periods identified by the EWI as state downturns-each extending from a peak in New Jersey's economic activity to a trough - are set off by vertical bands (although in the case of the earliest state downturn in the chart, only the right-hand band is shown). Periods identified as national recessions by the National Bureau of Economic Research are shaded in green.

The disparities in the onset and duration of the state and national contractions are very marked. The April 1974 peak in the state's economic activity occurred a full seven months after the peak in national activity, and the downturn lasted through June 1975-three months later than the national trough. The timing of the state's two downturns in the early 1980 s was roughly similar to that of the two national downturns, although New Jersey's slowdown was much milder than the nation's. The most recent downturn in the state's economic activity, in the

\section{Chart 1}

\section{Indexes of Economic Activity: New Jersey}

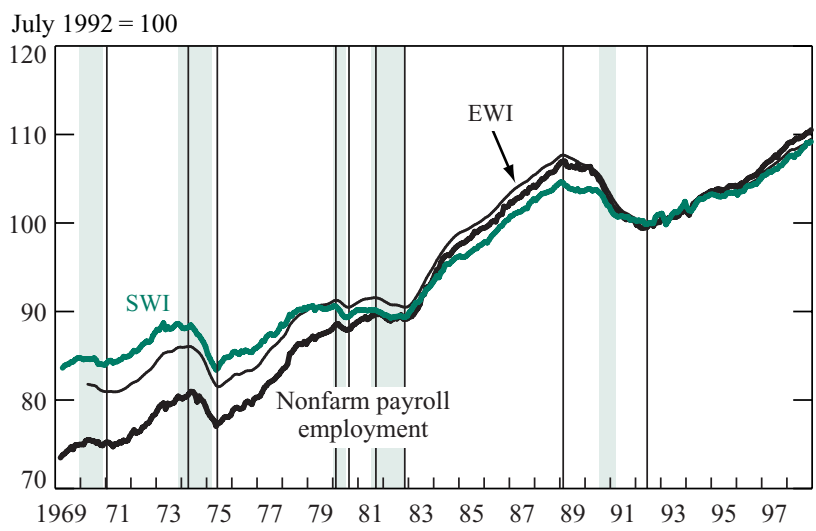

Sources: New Jersey Department of Labor; authors' calculations.

Note: The shaded areas indicate periods designated national recessions by the NBER; the bands mark periods identified as state downturns by the EWI late 1980 s, began much earlier and lasted considerably longer than the national downturn. The start of this downturn preceded the national downturn by more than a year, and the recovery began more than a year after the trough in national activity was reached.

Looking back, we see that the coincident indexes clearly identify New Jersey's peaks and troughs in economic activity over the past two decades. Three downturns occurred between 1974 and 1982: the April 1974 peak to the June 1975 trough, the February 1980 peak to the August 1980 trough, and the September 1981 peak to the November 1982 trough. The boom in the state during much of the 1980s is seen in the sharp and steady increases in the indexes throughout this period. A significantly more prolonged downturn - forty-two months-began in February 1989 and lasted through June 1992. Our indexes suggest that the New Jersey economy returned to its 1989 cyclical peak level of activity in June 1997 and has risen steadily since then.

A breakdown of New Jersey's coincident indexes into their component series can shed some light on the forces influencing the state's economy. The general cyclical pattern seen in the simple weighted index and the estimated weighted index is evident in each of the four series used to compute the composite numbers (Chart 2). Currently, these indexes confirm that the state's recovery from the early 1990s downturn shows little sign of letting up: real earnings and nonfarm payroll employment have each surpassed their previous peaks, and the unemployment rate is only modestly above its 1989 low. The overall upward trend in the two indexes reflects the strong trends in the real earnings and employment series and a mild upward trend in the average weekly hours worked in manufacturing series.

Using New Jersey as an example, we demonstrate how our two coincident indexes can offer a richer assessment of a regional economy than the nonfarm payroll series alone. On the one hand, nonfarm payroll employment - the most commonly used proxy for overall economic activity in the state- shows a cyclical pattern similar to that of our two indexes and corresponds particularly closely to the EWI for much of the 1980s and early 1990s. On the other hand, during New Jersey's current recovery, which began in 1992, payroll employment has risen at a somewhat faster pace than either the SWI or the EWI. The relatively slower expansion suggested by the coincident indexes likely reflects developments in two of the index components: a modest decline in 1995 in the average weekly hours worked in manufacturing and a drop-off in 1997 in the rate of 
Chart 2

\section{Index Components: New Jersey}
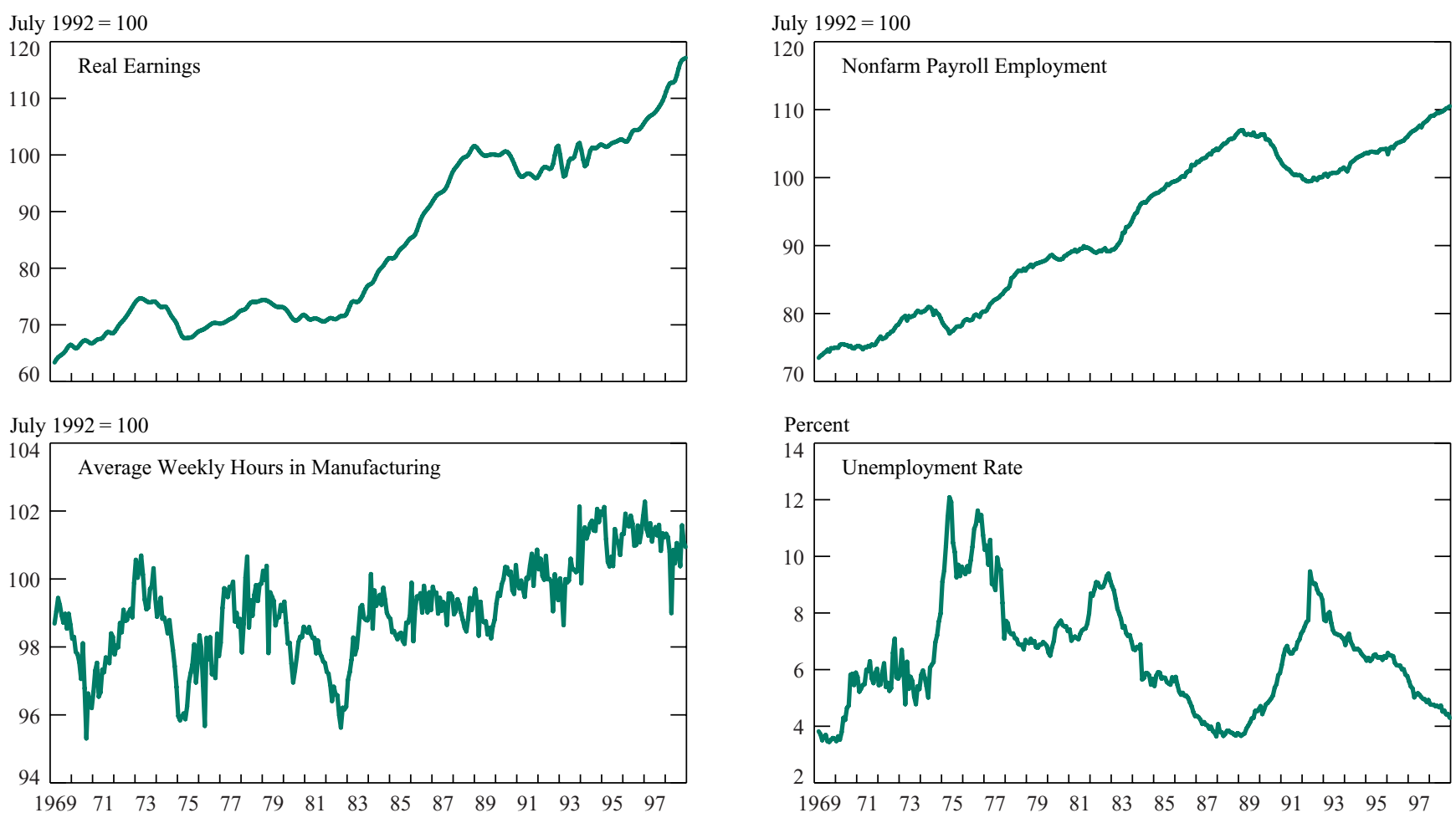

Sources: U.S. Department of Commerce; New Jersey Department of Labor; authors' calculations.

decline in the unemployment rate. The close correspondence with the EWI before 1993 suggests that the nonfarm payroll employment series is a reasonably good shorthand indicator of economic activity. However, the post-1993 divergence between our indexes and the series also suggests that an exclusive reliance on nonfarm payroll employment might give a less comprehensive picture of New Jersey's current expansion than would the use of a broader index.

\section{New York State}

Our coincident indexes show that New York State's business cycles differ from the national pattern of economic activity with regard to timing, duration, and turning points. For example, the estimated weighted index shows that the downturn in the state's economy following a peak in late 1973 lasted roughly eighteen months longer than the national recession (Chart 3). The state's downturns in 1980 and 1982 were roughly similar in length to the national recessions, although there were differences in the exact dates of the peaks and troughs. The starkest difference between the downturns in New York State and the nation, however, occurred at the end of the 1980s. The state economy peaked in May 1989 and declined through 1991, reaching a trough in November 1992. In contrast, the national recession was wholly contained within the 1990-91 period.

Our indexes reveal four distinct downturns in the New York State economy since the 1973 peak in activity. Two lasted more than two years: November 1973-June 1976 and May 1989-November 1992. The other two were shorter, lasting seven months and seventeen months, respectively: February 1980-September 1980 and September 1981February 1983. The indexes also show a sharp upswing in economic activity from 1983 through 1989. However, while the two indexes for New York State exhibit broadly similar patterns of cyclical economic activity, there are differences as great as eight months at some turning points.

Compared with the simple weighted index, the estimated weighted index for New York State places greater weight on nonfarm payroll employment, average weekly hours in manufacturing, and real earnings, and less weight on the unemployment rate (see table). In the boom 
Chart 3

\section{Indexes of Economic Activity: New York State}

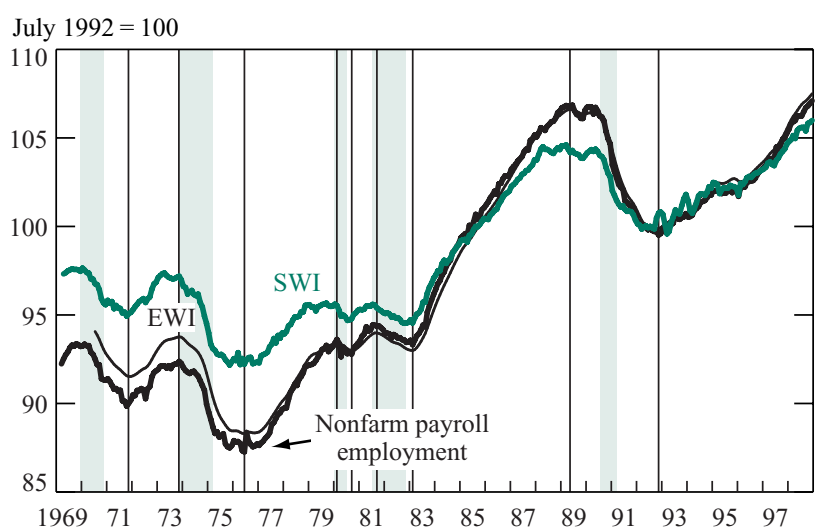

Sources: New York State Department of Labor; authors' calculations.

Note: The shaded areas indicate periods designated national recessions by the NBER; the bands mark periods identified as state downturns by the EWI.

period of the 1980s and again in the upturn in the 1990s, payroll employment expanded at a moderate clip. Manufacturing hours jumped to a higher level and then generally sustained the new pace. As a result, both the EWI and the nonfarm payroll employment series advanced more rapidly than the SWI during these periods. The SWI's slower pace appears to reflect the smaller weights given to payroll employment and manufacturing hours and the greater importance accorded the unemployment rate. Beginning in 1995, the drop in the unemployment rate slowed for several years, a development that is likely to have limited the increase in the SWI. Despite the differences in the SWI, the EWI, and the payroll employment series, each series for New York State had surpassed its previous peak by the end of 1998.

\section{New York City}

With an economy similar in size to that of New Jersey, New York City merits a separate set of coincident indexes. A comparison of business cycles in the city

\section{Weighting of Index Components}

\begin{tabular}{lcrrrrrc} 
& \multicolumn{2}{c}{ New Jersey } & \multicolumn{2}{c}{ New York State } & New York City \\
\cline { 2 - 7 } & SWI & EWI & SWI & EWI & SWI & EWI \\
\hline $\begin{array}{l}\text { Nonfarm payroll } \\
\text { employment }\end{array}$ & 33.1 & 36.4 & 36.4 & 43.5 & 66.0 & 78.3 \\
$\begin{array}{c}\text { Average weekly hours } \\
\text { in manufacturing }\end{array}$ & 16.9 & 40.1 & 15.0 & 32.2 & 19.0 & 2.4 \\
Unemployment rate & 28.3 & 16.0 & 37.8 & 11.5 & - & - \\
Real earnings & 21.7 & 7.4 & 10.9 & 12.9 & 15.0 & 19.3 \\
\hline
\end{tabular}

Source: Authors' calculations. with those of the nation indicates that the timing of the city's downturns differed markedly from the timing of the national recessions. In fact, activity in New York City barely slipped during the national recession in 1980 and slowed only mildly during the recession in 1981-82. In contrast, the city's 1989-92 downturn was substantially longer than the nation's.

Both coincident indexes depict the city's economy as bottoming out in 1977, declining modestly in 1980, and then expanding steadily into late 1981 (Chart 4). The strength of the city's economy in the 1980s is seen clearly in the steady growth in the indexes from the end of 1982 to early 1989 . The economy did contract, however, at the beginning and end of the 1980s: a downturn occurred from October 1981 to December 1982 and a longer one extended from February 1989 to November 1992.

As we saw in our discussion of New Jersey and New York State, indexes that combine information from a variety of local indicators can provide a fuller assessment of a local economy than a simple payroll employment count. In the case of New York City, the movements in the nonfarm payroll employment series are broadly similar to those of our indexes. However, while the job count shows that the city has failed to recover the jobs lost in the 1989-92 downturn, the coincident indexes show that overall activity has neared (EWI) or exceeded (SWI) its previous peak. Here our indexes potentially offer a more comprehensive reading of recent economic activity because they take into account a jump in manufacturers' average weekly hours and a significant increase in the growth of real earnings since 1995.

\section{Chart 4}

\section{Indexes of Economic Activity: New York City}

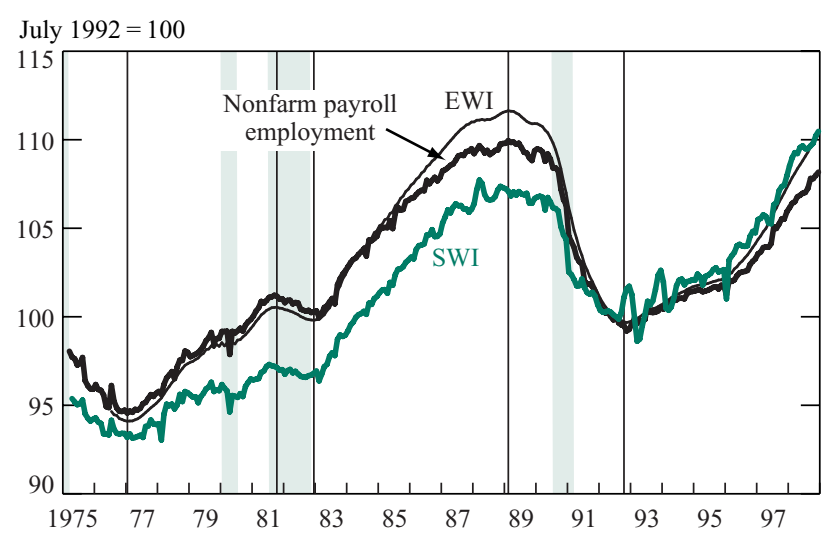

Sources: New York State Department of Labor; authors' calculations.

Note: The shaded areas indicate periods designated national recessions by the NBER; the bands mark periods identified as city downturns by the EWI. 


\section{Conclusion}

Our coincident indexes appear to be effective tools for examining the pattern of economic activity in the New York-New Jersey region. Despite differences in their methodology and construction, the simple weighted index and the estimated weighted index exhibit similar cyclical patterns in New Jersey, New York State, and New York City, and generally allow for a straightforward dating of regional business cycles. The indexes also enable us to compare regional and national business cycles-a process that reveals that the timing and duration of the regional cycles are indeed different from those of the national cycles. Finally, the similarity in the movements of our coincident indexes and the nonfarm payroll employment series implies that the payroll series is a reasonably good shorthand economic indicator; however, the coincident indexes provide a broader view of cyclical movements in the economy than does the payroll series alone.

Going forward, our work on coincident indexes lays the groundwork for the development of leading indexes for the New York-New Jersey region. For instance, these indexes could forecast the EWI over a six-to-ninemonth horizon by using current and past values of variables thought to lead movements in this series. ${ }^{6}$ As a result, the leading indexes could offer timely signals of an impending downturn or an emerging upturn in the region.

\section{NOTES}

The authors would like to thank Alan Clayton-Matthews of the University of Massachusetts at Boston and Ted Crone of the Federal Reserve Bank of Philadelphia for their assistance in estimating the EWI

1. The national coincident index is now maintained and reported by the Conference Board (see Conference Board [1996] for a detailed description of its construction). It differs from two other national composite indexes - the leading index of activity, whose movements signal future changes in the state of the economy, and the lagging index of activity, whose movements follow changes in the state of the economy.

2. Federal Reserve System economists have constructed regional coincident indexes for Texas (Phillips 1988) and for New Jersey, Delaware, and Pennsylvania (Crone 1994).

3. This argument is consistent with the view that because business cycles are broad-based in nature, they should be evaluated using information from various economic indicators.

4. Our indexes for New Jersey and for New York State cover the 1969-98 period; our indexes for New York City cover the 1975-98 period, owing to data limitations.

5. The New York City unemployment rate has tended to move procyclically with the economy in recent years. Changes in welfare regulations in the mid-1990s may have resulted in a surge of new entrants into the labor force and led to unique changes in the relationship between various measures of economic activity and the unemployment rate (Bram, Brauer, and Miranda 1997).

6. For forecasting purposes, we can use data derived from sources such as help-wanted ads, regional consumer confidence reports, and housing starts to supplement such financial variables as the spread between long- and short-term interest rates.

\footnotetext{
REFERENCES

Bram, Jason, David Brauer, and Elizabeth Miranda. 1997. "New York City's Unemployment Picture.” Federal Reserve Bank of New York Current Issues in Economics and Finance 3, no. 14.

Conference Board. 1996. "Technical Appendix Calculating the Composite Index.” Business Cycle Indicators, December.

Crone, Theodore M. 1994. "New Indexes Track the State of the States.” Federal Reserve Bank of Philadelphia Business Review, January-February.

Phillips, Keith R. 1988. "New Tools for Analyzing the Texas Economy: Indexes of Coincident and Leading Economic Indicators." Federal Reserve Bank of Dallas Economic Review, July.

Stock, James H., and Mark W. Watson. 1989. "New Indexes of Coincident and Leading Economic Indicators." NBER Macroeconomics Annual. Cambridge, Mass.: MIT Press.
}

The views expressed in this article are those of the authors and do not necessarily reflect the position of the Federal Reserve Bank of New York or the Federal Reserve System.

Second District Highlights, a supplement to Current Issues in Economics and Finance, is published by the Research and Market Analysis Group of the Federal Reserve Bank of New York. Dorothy Meadow Sobol is the editor. Back issues of Second District Highlights are available at http://www.ny.frb.org/curr_iss/sec_dis. 